\title{
Photofuel cells using glucose-doped titania
}

Hiromasa Nishikiori,* Kazuhiro Isomura, Yohei Uesugi, and Tsuneo Fujii

Department of Environmental Science and Technology, Graduate School of Science and

Technology, Shinshu University, 4-17-1 Wakasato, Nagano 380-8553, Japan

Corresponding author: Hiromasa Nishikiori

Tel: +81-26-269-5536

Fax: +81-26-269-5550

E-mail: nishiki@shinshu-u.ac.jp

Department of Environmental Science and Technology, Graduate School of Science and Technology, Shinshu University, 4-17-1 Wakasato, Nagano 380-8553, Japan 


\begin{abstract}
Glucose-doped titania electrodes were prepared from titanium alkoxide sols containing glucose in order to examine the validity of the fuel material concentrated on the photocatalyst surface. The observed photocurrent and $\mathrm{CO}_{2}$ and $\mathrm{H}_{2} \mathrm{O}$ productions indicated that the oxidation of the glucose enhanced the generation of electricity during the UV irradiation. Steam treatment of the electrodes improved the glucose oxidation and the photocurrent. However, refluxing of the precursor sol did not improve them. Not only the titania conductivity, but also the contact between the glucose and titania is important in order to obtain a high photofuel electric conversion. The concentration of the fuel material on the photocatalyst surface improved the energy conversion efficiency.
\end{abstract}

Keywords: Photofuel cell; Titania; Photocatalysis; Glucose; Oxidation 


\section{Introduction}

Dye-sensitized solar cells employ dye-adsorbed titania as the working electrodes [1-3]. Dye-doped amorphous titania gels are prepared without heating from a titanium alkoxide sol containing the dye molecules by the sol-gel method [4-7]. The characteristics of the dye-doped titania system are a high dispersion of the dye and a high contact area between the dye and titania. The dye-doped titania system is an interesting material for the basic study of dye-sensitized solar cells because hydrothermal treatments cause its crystallization and changes in the titania structure and dye-titania bond character.

The dye-doped nanocrystalline titania electrodes were prepared from an untreated or refluxed [7-12] titanium alkoxide solution containing the dye. These electrodes were then steam-treated [13-16]. The crystallization of the amorphous titania to anatase was achieved by hydrothermal treatment at a low temperature because water molecules catalyzed the rearrangement of the $\mathrm{TiO}_{6}$ octahedra [13]. We then studied the photoelectric conversion properties of the dye-doped nanocrystalline titania films. The conversion efficiency was improved by enhancement of the dye-titania interaction due to the hydrothermal treatments [4-7].

Such photocatalyst titania films are also useful as photofuel cell electrodes to generate electricity by oxidizing the fuel materials during UV irradiation [17-22]. Photofuel cells perform both the disposal of organic wastes and electric generation. The photofuel action electrodes generally act in the liquid phase containing the fuel material. In such systems, the concentration of the fuel material on the photocatalyst surface is one of the parameters that can improve the energy conversion efficiency. We tried to prepare the glucose-doped titania electrodes by such hydrothermal procedures and investigate their photoelectric properties. The glucose-doped titania is a model of the fuel material concentrated in the 
porous titania when using glucose as a biomass fuel material. After the glucose is completely consumed by the photocatalytic reaction, fresh glucose can be supplied by immersing the titania electrode in its solution during ultrasonic irradiation due to its porous structure. These were studied in order to examine the interaction between the glucose and titania rather than the practical value of the glucose-doped titania.

\section{Experimental}

\subsection{Materials}

Titanium tetraisopropoxide (TTIP), nitric acid (69-70\%), ethanol, iodine, and lithium iodide of S or reagent grade were obtained from Wako Pure Chemicals. The dry nitrogen gas was obtained from Okaya Sanso. These materials were used without further purification. The water was deionized and distilled (Yamato WG23).

\subsection{Sample preparation}

The sol-gel reaction system was prepared by mixing $5.0 \mathrm{~cm}^{3}$ of TTIP, $25.0 \mathrm{~cm}^{3}$ of ethanol, $0.21 \mathrm{~cm}^{3}$ of water, and $0.21 \mathrm{~cm}^{3}$ of nitric acid as the catalyst for the sol-gel reaction and labeled SG. The mixing was carried out in a nitrogen atmosphere. Glucose was dissolved in the SG to a final concentration of $1.0 \times 10^{-2} \mathrm{~mol} \mathrm{dm}^{-3}$ and this system was labeled $\mathrm{SG}(\mathrm{G})$. The dip-coated thin films were made from the systems in which the sol-gel reaction proceeded for 1 day to prepare the electrodes.

In order to prepare the electrode samples coated with the crystalline titania, the glass plates with the ITO transparent electrode were dip-coated with the SG and then heated at 500 ${ }^{\circ} \mathrm{C}$ for 30 min. These electrodes were labeled E0. Furthermore, the working electrodes were prepared in which the E0 was dip-coated with the SG(G) and SG. These electrodes were labeled WE-N(G) and WE-N, respectively. 
Water was heated at $100{ }^{\circ} \mathrm{C}$ and then these electrode samples were exposed to its steam for $2 \mathrm{~h}$. The steam pressure was about $100 \mathrm{kPa}$ [4-7]. The steam-treated working electrodes prepared from the $\mathrm{SG}(\mathrm{G})$ and $\mathrm{SG}$ were labeled WE-N-s(G) and WE-N-s, respectively.

The other sol-gel reaction system was prepared by mixing $30.0 \mathrm{~cm}^{3}$ of TTIP, $5.0 \mathrm{~cm}^{3}$ of ethanol, $180.0 \mathrm{~cm}^{3}$ of water, and $2.0 \mathrm{~cm}^{3}$ of concentrated nitric acid in order to examine the effect of refluxing the system on the spectroscopic and photoelectric properties of the electrode sample prepared from this system. The mixing was carried out in a nitrogen atmosphere. Glucose was dissolved in this sol-gel system $\left(1.0 \times 10^{-2} \mathrm{~mol} \mathrm{dm}^{-3}\right)$ and refluxed at $80^{\circ} \mathrm{C}$ for $12 \mathrm{~h}$, which was labeled SG-R(G) [7-9]. The glucose-free system was also refluxed at $80^{\circ} \mathrm{C}$ for $12 \mathrm{~h}$, which was labeled SG-R. The total volume of the SG-R(G) or SG-R was much greater than that of the $\mathrm{SG}(\mathrm{G})$ or $\mathrm{SG}$ because a larger reactor was used for the refluxing. A higher relative amount of water was required for complete hydrolysis of the TTIP during refluxing. The SG-R(G) and SG-R were spread on the E0 by dip-coating, which were labeled WE-R(G) and WE-R, respectively. These working electrodes were also steam-treated under the same conditions in order to clarify the difference between the influence of the steam treatment and refluxing on the crystallization of the titania gel and the spectroscopic and photoelectric properties of the electrode. These working electrodes were labeled WE-R-s(G) and WE-R-s, respectively.

The titania films, F-N, F-N-s, F-R, and F-R-s, and the glucose-doped titania films, F-N(G), F-N-s $(G), F-R(G)$, and F-R-s(G), were also prepared on glass plates without ITO for XRD analyses.

\subsection{Characterization of samples}

The prepared samples were characterized by SEM observations (Hitachi S-4100) and XRD analysis using CuK $\alpha$ radiation (Rigaku RINT-2000V). The layer thickness of the 
electrode samples was estimated from their cross section by SEM observation. The size of the crystallites of each sample was estimated from its full-width at half-maximum of the $25.3^{\circ}$ peak in the XRD pattern using Sherrer's equation, $\mathrm{D}=0.9 \lambda / \beta \cdot \cos \theta$. The iodine-based electrolyte $\left(\mathrm{I}_{2} / \mathrm{LiI}\right)$ was allowed to soak into the space between the working electrode sample and the counter Pt electrode. The $I-V$ curves of the electrodes were measured during irradiation by a $150 \mathrm{~W}$ Xe short arc lamp (Hokuto Denko HSV-100). The $I-V$ curves of the glucose-free titania electrodes were also measured using an iodine-based electrolyte containing glucose $\left(1.0 \times 10^{-2} \mathrm{~mol} \mathrm{dm}^{-3}\right)$. In this study, a nonaqueous iodine-based electrolyte was used for the electrochemical measurement in order to induce the oxidation and reduction on/near the titania surface without producing hydrogen or the superoxide anion radical on the counter electrode. The concentrations of $\mathrm{CO}_{2}$ and $\mathrm{H}_{2} \mathrm{O}$ produced during the photocatalytic degradation in an IR spectroscopic cell were estimated by an FTIR analysis (Shimadzu IRPrestige-21) [23-26].

\section{Results and discussion}

\subsection{Characterization of the samples}

Figure 1 shows the SEM images of the glucose-doped titania electrodes, WE-R-s(G) and WE-R(G). No particles were observed in the electrodes, WE-N, WE-N(G), and WE-N-s(G), and they appeared amorphous (data not shown). The electrode prepared from the refluxed sol, WE-R(G), mainly consists of ca. $10 \mathrm{~nm}$ particles. The steam-treated electrode, WE-R-s $(\mathrm{G})$, consists of 10-30 nm particles, which were grown by the action of water molecules. The other steam-treated electrodes except for WE-N-s $(\mathrm{G})$ also consisted of 10-30 nm particles similar to WE-R-s(G). The thickness of the unheated titania layer of the electrodes was ca. $350 \mathrm{~nm}$ and slightly changed after the steam treatment. 
(Figure 1)

Figure 2 shows the XRD patterns of the titania films F-N, F-N-s, F-R, and F-R-s, and the glucose-doped titania films, F-N(G), F-N-s(G), F-R(G), and F-R-s(G). The film prepared from the untreated sol, F-N and F-N(G), exhibited no diffraction peak and was found to be amorphous. An anatase-type crystal was produced by refluxing of the sol and steam treatment of the gel because the $2 \theta$ peak at around $25^{\circ}$ was observed in their XRD patterns. However, the peaks were broader for the films containing the glucose than for the glucose-free films. The crystallite sizes of the films estimated by XRD analysis are summarized in Table 1. The sizes were smaller for the glucose-containing films than for the glucose-free films. This result indicates that glucose molecules prevented the crystal growth of the titania [5]. The refluxing of the precursor sol more effectively promoted the crystal growth than steam treatment of the electrodes. Glucose molecules were expected to be more highly dispersed in the untreated sol than in the refluxed sol. The dispersion of glucose molecules in the films reflects that in the sol. The glucose dispersion influenced the titania crystallization process as reported for the dye-doped systems [7]. The organic molecules were doped and dispersed into the titania on a molecular level during the sol-gel process [27-30]. Therefore, the molecular aggregates cannot expand the pore size of the titania. The pore size or porosity does not depend on the presence of glucose molecules.

(Figure 2)

\subsection{Photofuel electric conversion}

Figure 3 shows the $I-V$ curves of the titania electrodes, WE-N, WE-N-s, WE-R, and WE-R-s, and the glucose-doped titania electrodes, WE-N(G), WE-N-s $(\mathrm{G})$, WE-R(G), and WE-R-s(G), during light irradiation. Higher short-circuit photocurrent values were clearly observed for the glucose-doped electrode than for the normal titania electrode. With respect to the glucose-free electrodes, the electrode prepared from the refluxed sol, WE-R, 
was found to consist of specific crystalline particles and exhibited a higher photocurrent than the amorphous electrode, WE-N. This is because the crystallinity is correlated with the electric conductivity. However, the photocurrent of the glucose-containing electrode prepared from the refluxed sol, WE-R(G), was almost same as that of the glucose-containing amorphous electrode, WE-N(G). On the other hand, the steam treatment certainly improved the photocurrent. These results indicated that the conversion efficiency was improved by not only the enhancement in the electric conductivity due to crystallization of the titania. The steam treatment improved the photofuel cell reaction and performance even though the crystallinity was not high in the treated titania films. The steam treatment of the electrode was more effective for the photofuel cell reaction than the refluxing of the precursor sol.

(Figure 3)

Figure 4 shows the $I-V$ curves of the titania electrodes, WE-N-s and WE-R-s, using the electrolyte with and without glucose in order to evaluate the oxidation of the glucose in the liquid phase during light irradiation. The short-circuit photocurrent values using the glucose-containing electrolyte were slightly higher than those using the normal electrolyte. This result indicates that the oxidation of glucose in the liquid phase was inefficient because its concentration on the titania surface was very low. The concentration of the fuel material on the photocatalyst surface is an important parameter to improve the energy conversion efficiency. The glucose molecules should be oxidized with oxygen by holes on the titania surface and produce protons, which should be reduced with oxygen due to the electrolyte as follows:

$$
\begin{aligned}
& \mathrm{C}_{6} \mathrm{H}_{12} \mathrm{O}_{6}+3 \mathrm{O}_{2}+12 \mathrm{~h}^{+} \rightarrow 6 \mathrm{CO}_{2}+12 \mathrm{H}^{+} \\
& 12 \mathrm{H}^{+}+3 \mathrm{O}_{2}+12 \mathrm{e}^{-} \rightarrow 6 \mathrm{H}_{2} \mathrm{O}
\end{aligned}
$$

(Figure 4) 


\subsection{Oxidation of glucose}

$\mathrm{CO}_{2}$ and $\mathrm{H}_{2} \mathrm{O}$ were observed as the photocatalytic products from the glucose-doped titania electrodes during light irradiation. Figure 5 shows the time course of the concentrations of $\mathrm{CO}_{2}$ and $\mathrm{H}_{2} \mathrm{O}$ produced during the photocatalytic degradation of glucose for each glucose-doped titania electrode. Table 2 shows the relationship between the average $\mathrm{CO}_{2}$ and $\mathrm{H}_{2} \mathrm{O}$ production rates for each glucose-doped titania electrode and the difference between the short-circuit photocurrent density values for the titania and glucose-doped titania electrodes. The average $\mathrm{CO}_{2}$ and $\mathrm{H}_{2} \mathrm{O}$ production rates are almost the same, indicating that the glucose molecules are completely oxidized on the titania surface. These rates are certain to have increased by the steam treatment, corresponding to the increase in the photocurrent value. However, the reflux did not improve them. In the electrode prepared from the refluxed sol, the $\mathrm{CO}_{2}$ and $\mathrm{H}_{2} \mathrm{O}$ production rate was slow based on the photocurrent value. This is due to the significant contribution of the titania crystallinty to the photocurrent generation. The electrodes prepared from the untreated sol exhibited a higher performance than those prepared from the refluxed sol because the glucose molecules were highly dispersed in the electrodes. In systems, such as dye-sensitized titania solar cells, the strong interaction and complex formation between the organic molecules and titania caused the ligand-to-metal charge transfer (LMCT) interaction and a fast electron injection into the titania conduction band [31-33]. The reactivity was influenced by the contact between the glucose and titania [7].

(Figure 5, Table 2)

\section{Conclusions}

The glucose-doped titania electrodes were prepared from titanium alkoxide sols 
containing glucose by hydrothermal procedures and their photoelectric properties were investigated in order to examine the interaction between the glucose and titania. The glucose-doped titania electrodes were prepared from the glucose-containing titanium alkoxide sol untreated and refluxed at $80^{\circ} \mathrm{C}$. These electrodes were untreated and steam-treated. The higher photocurrent values were clearly observed in the glucose-doped electrode than in the normal titania electrode. This indicates that the oxidation of the glucose enhanced the generation of electricity. $\quad \mathrm{CO}_{2}$ and $\mathrm{H}_{2} \mathrm{O}$ were observed as the photocatalytic products from the glucose-doped titania electrodes during light irradiation. The steam treatment of the electrodes improved the glucose oxidation and the photocurrent. However, the reflux of the precursor sol did not improve the photofuel cell performance because the glucose dispersion was lower. Not only the titania conductivity due to its crystallinty, but also the contact between the fuel material and titania due to its dispersion in the titania, is important to have a high photofuel electric conversion. The glucose-doped titania is a valid model of the fuel material concentrated in the porous titania when using glucose as a fuel material. The concentration of the fuel material on the photocatalyst surface is an important parameter to improve the energy conversion efficiency.

\section{References}

[1] B. O’Regan, M. Grätzel, Nature 353 (1991) 737-740.

[2] M. K. Nazeeruddin, A. Kay, I. Rodicio, R. Hamphry-Baker, E. Müeller, P. Liska, N. Vlachopoulos, M. Grätzel, J. Am. Chem. Soc. 115 (1993) 6382-6390.

[3] M. Grätzel, J. Photochem. Photobiol. C: Photochem. Rev. 4 (2003) 145-153.

[4] H. Nishikiori, N. Tanaka, T. Kitsui, T. Fujii, J. Photochem. Photobiol. A: Chem. 179 (2006) 125-129. 
[5] T. Kitsui, H. Nishikiori, N. Tanaka, T. Fujii, J. Photochem. Photobiol. A: Chem. 192 (2007) 220-225.

[6] H. Nishikiori, W. Qian, M. A. El-Sayed, N. Tanaka, T. Fujii, J. Phys. Chem. C 111 (2007) 9008-9011.

[7] H. Nishikiori, Y. Uesugi, N. Tanaka, T. Fujii, J. Photochem. Photobiol. A: Chem. 207 (2009) 204-208.

[8] Y. Hu, C. Yuan, J. Crystal Growth 274 (2005) 563-568.

[9] L. Ge, M. Xu, M. Sun, H. Fang, J. Sol-Gel Sci. Technol. 38 (2006) 47-53.

[10] S. Liu, N. Jaffrezic, C. Guillard, Appl. Surface Sci. 255 (2008) 2704-2709.

[11] S. Zhang, Z. Chen, Y. Li, Q. Wang, L. Wan, Y. You, Mater. Chem. Phys. 107 (2008) $1-5$

[12] S. Priya, J. Robichaud, M. C. Méthot, S. Balaji, J. M. Ehrman, B. L. Su, Y. Djaoued, J. Mater. Sci. 44 (2009) 6470-6483.

[13] K. Yanagisawa, J. Ovenstone, J. Phys Chem. B 103 (1999) 7781-7787.

[14] K. Y. Chiu, M. H. Wong, F. T. Cheng, H. C. Man, Appl. Surface Sci. 253 (2007) $6762-6768$

[15] D. P. Serrano, G. Calleja, R. Sanz, P. Pizarro, J. Mater. Chem. 17 (2007) 1178-1187.

[16] M. H. Wong, F. T. Cheng, H. C. Man, J. Am. Ceram. Soc., 91 (2008) 414-420.

[17] M. Kaneko, J. Nemoto, H. Ueno, N. Gokan, K. Ohnuki, M. Horikawa, R. Saito, T. Shibata, Electrochem. Commun. 8 (2006) 336-340.

[18] H. Ueno, J. Nemoto, K. Ohnuki, M. Horikawa, M. Hoshino, M. Kaneko, J. Appl. Electrochem. 39 (2009) 1897-1905.

[19] M. Antoniadou, P. Lianos, Catal. Today 144 (2009) 166-171.

[20] M. Antoniadou, D. I. Kondarides, D. Labou, Catal. Lett. 129 (2009) 344-349.

[21] M. Antoniadou, P. Lianos, Appl. Catal. B: Environ. 99 (2010) 307-313. 
[22] M. Antoniadou, D. I. Kondarides, D. Labou, S. Neophytides, P. Lianos, Solar Energy Mater. Solar cells 94 (2010) 592-597.

[23] R. J. Haines, R. E. Wittrig, C. P. Kubiak, Inorg. Chem. 33 (1994) 4723-4728.

[24] R. A. Nicodemus, A. Tokmakoff, Chem. Phys. Lett. 449 (2007) 130-134.

[25] H. Nishikiori, M. Tagahara, L. Mukoyama, T. Fujii, Res. Chem. Intermed. 36 (2010) $947-957$.

[26] H. Nishikiori, M. Furukawa, T. Fujii, Appl. Catal. B: Environ. 102 (2011) 470-474.

[27] T. Fujii, H. Nishikiori, T. Tamura, Chem. Phys. Lett. 233 (1995) 424-429.

[28] H. Nishikiori, T. Fujii, J. Phys. Chem. B 101 (1997) 3680-3687.

[29] H. Nishikiori, S. Nagaya, N. Tanaka, A. Katsuki, T. Fujii, Bull. Chem. Soc. Jpn. 72 (1999) 915-921.

[30] H. Nishikiori, N. Tanaka, Y. Minami, A. Katsuki, T. Fujii, J. Photochem. Photobiol. A: Chem. 212 (2010) 62-67.

[31] M. Hilgendorff, V. Sundström, J. Phys. Chem. B 102 (1998) 10505-10514.

[32] G. Ramakrishna, H. N. Ghosh, J. Phys. Chem. B 105 (2001) 7000-7008.

[33] D. EL Mekkawi, M. S. A. Abdel-Mottaleb, Int. J. Photoenergy 7 (2005) 95-101. 
Table 1 Crystallite sizes of the titania films and glucose-doped titania films prepared from the normal sol and the refluxed sol.

\begin{tabular}{lclc}
\hline Sample & Crystallite size / nm & Sample & Crystallite size / nm \\
\hline N-s & 3.7 & N-s $(\mathrm{G})$ & - \\
N & - & $\mathrm{N}(\mathrm{G})$ & - \\
$\mathrm{R}-\mathrm{s}$ & 7.9 & $\mathrm{R}-\mathrm{s}(\mathrm{G})$ & 7.1 \\
$\mathrm{R}$ & 5.3 & $\mathrm{R}(\mathrm{G})$ & 4.2 \\
\hline
\end{tabular}

Table 2 Average $\mathrm{CO}_{2}$ and $\mathrm{H}_{2} \mathrm{O}$ production rates for each glucose-doped titania electrode and the difference between the short-circuit photocurrent density values for the titania and glucose-doped titania electrodes.

\begin{tabular}{lcccc}
\hline Sample & $\begin{array}{l}\text { Average } \mathrm{CO}_{2} \\
\text { rate } / \mathrm{mol} \mathrm{h}^{-1}\end{array}$ & production & $\begin{array}{l}\text { Average } \mathrm{H}_{2} \mathrm{O} \\
\text { rate } / \mathrm{mol} \mathrm{h}^{-1}\end{array}$ & $\begin{array}{c}\text { production } \\
\mathrm{N}-\mathrm{s}(\mathrm{G})\end{array}$ \\
$1.1 \times 10^{-7}$ & $1.1 \times 10^{-7}$ & $\begin{array}{l}\text { Photocurrent density / } \\
\mu \mathrm{Am}^{-2}\end{array}$ \\
$\mathrm{~N}(\mathrm{G})$ & $8.9 \times 10^{-8}$ & $9.6 \times 10^{-8}$ & 162 \\
$\mathrm{R}-\mathrm{s}(\mathrm{G})$ & $4.5 \times 10^{-8}$ & $4.6 \times 10^{-8}$ & 139 \\
$\mathrm{R}(\mathrm{G})$ & $1.3 \times 10^{-8}$ & $1.1 \times 10^{-8}$ & 107 \\
\hline
\end{tabular}




\section{Figure captions}

Figure 1. SEM images of the glucose-doped titania electrodes, (a) WE-R-s(G) and (b) WE-R(G).

Figure 2. XRD patterns of the titania films and glucose-doped titania films prepared from the normal sol and the refluxed sol.

Figure 3. $I-V$ curves of the glucose-doped titania electrodes observed during light irradiation.

Figure 4. $I-V$ curves of the glucose-doped titania electrodes, WE-N-s and WE-R-s, in the electrolyte with and without glucose during light irradiation.

Figure 5. Time course of the concentrations of (a) $\mathrm{CO}_{2}$ and (b) $\mathrm{H}_{2} \mathrm{O}$ in the gas phase during the photocatalytic degradation of glucose for each glucose-doped titania electrode. 
Figure 1
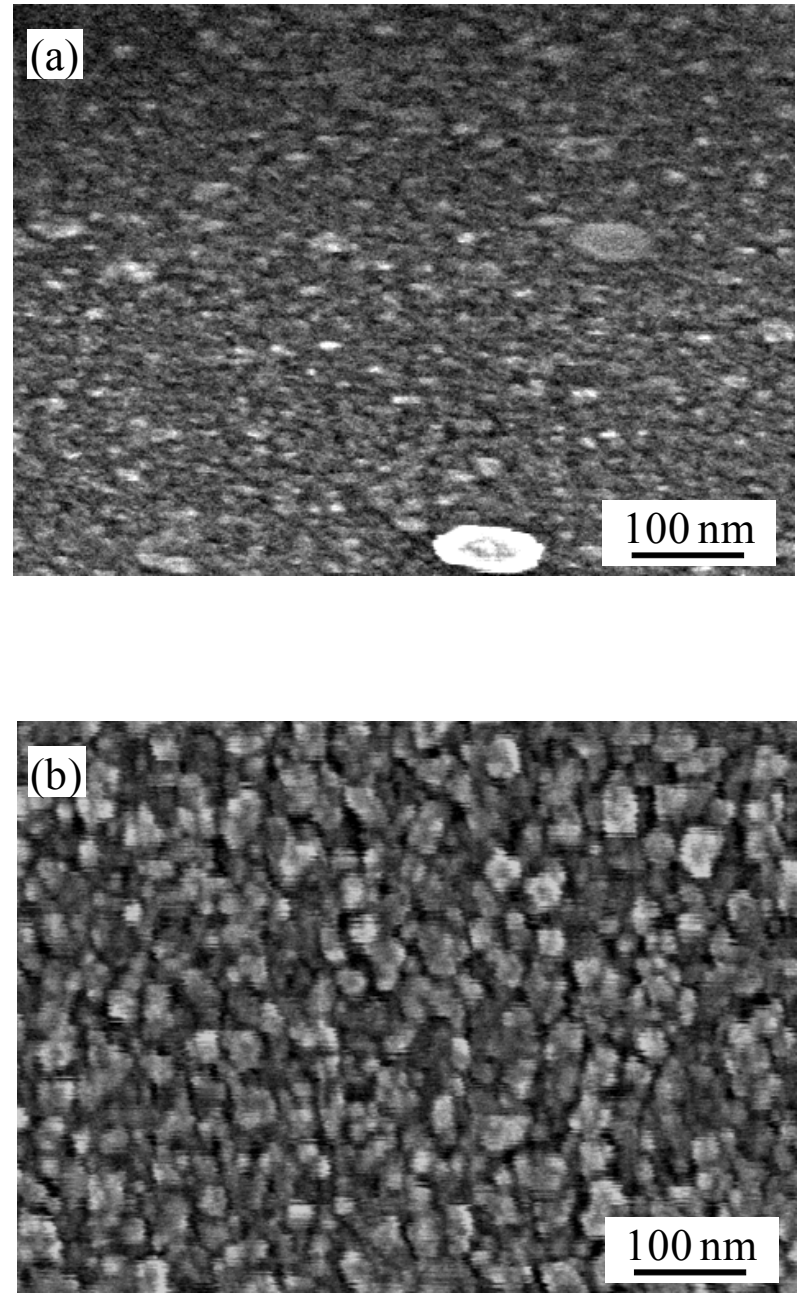
Figure 2
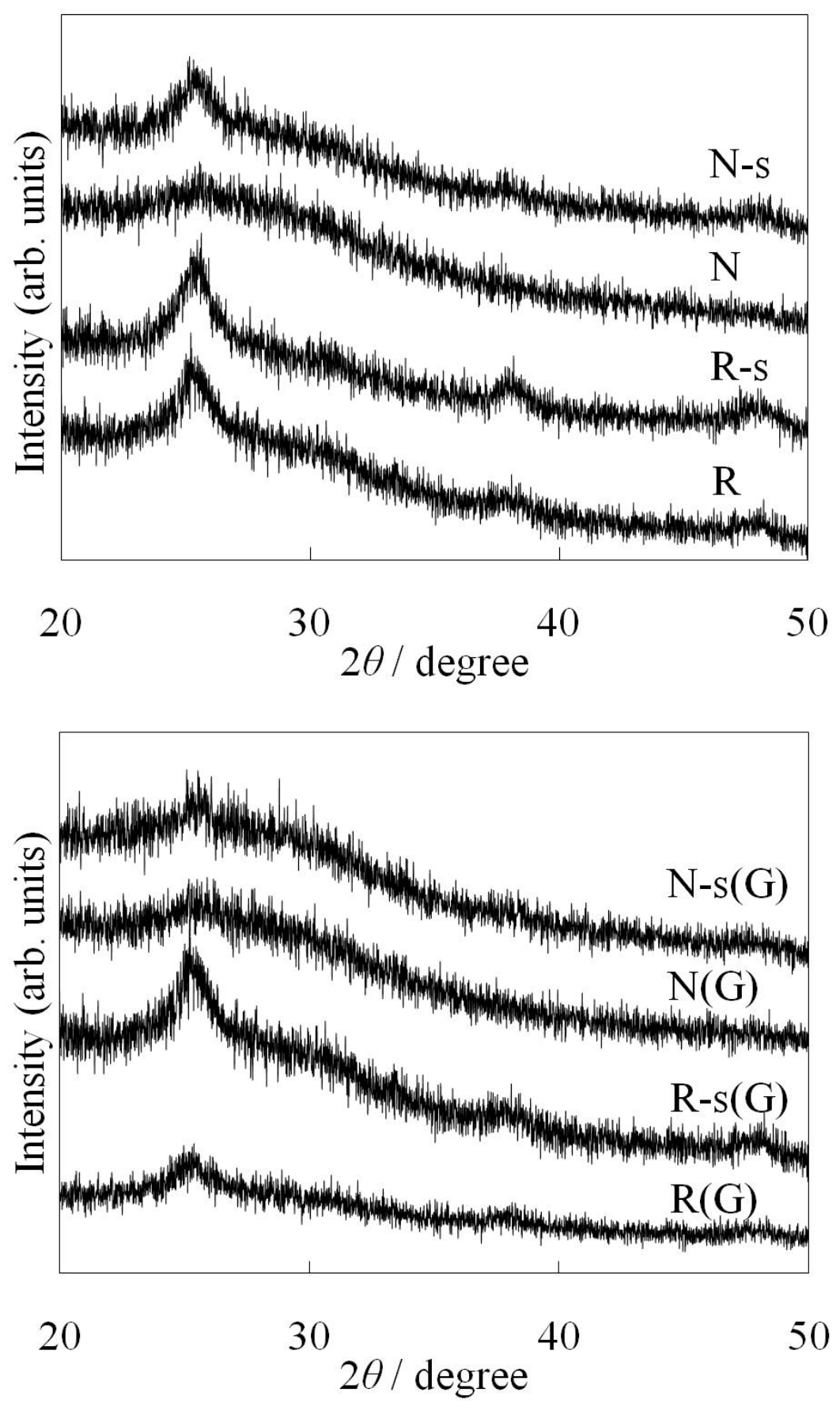
Figure 3
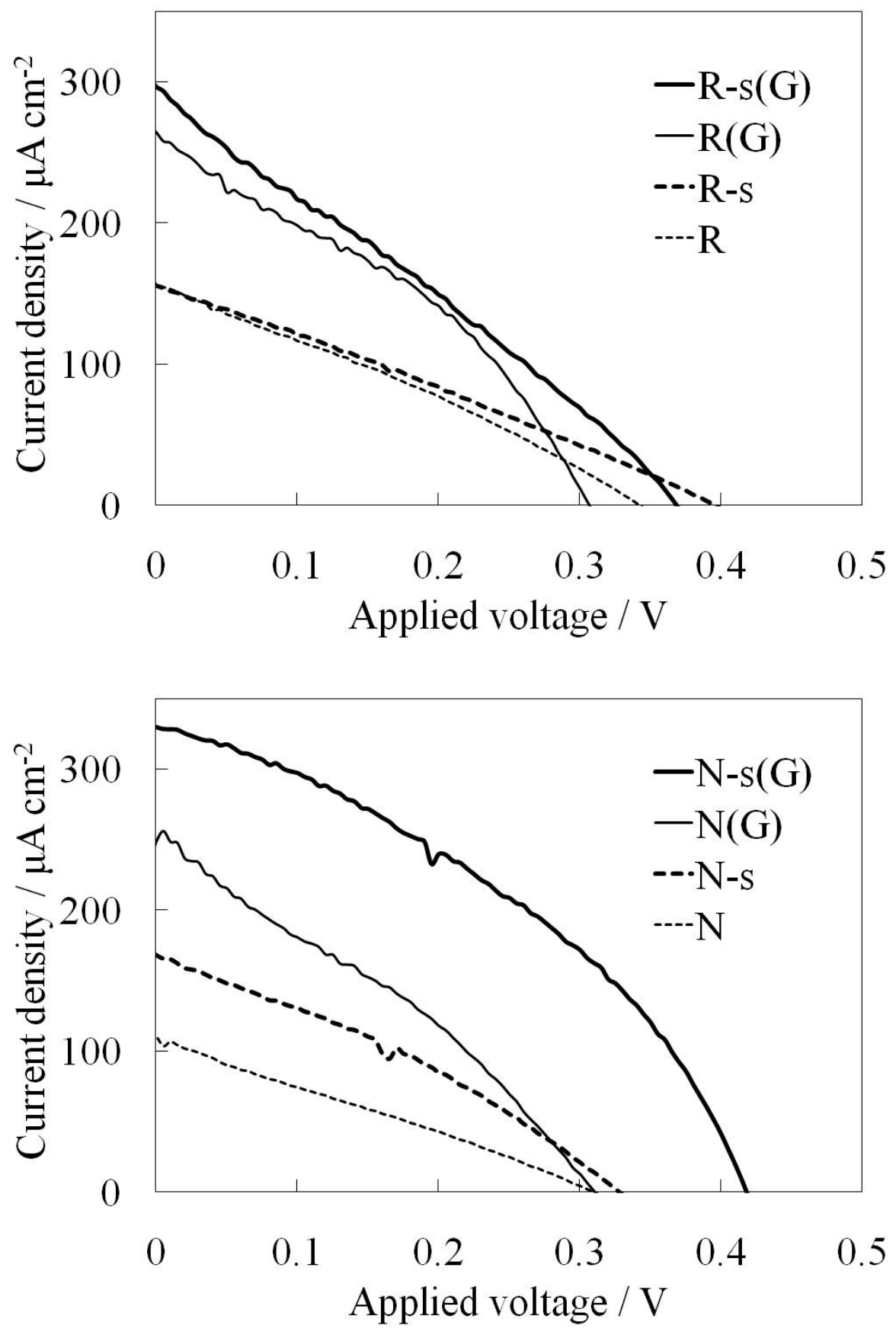
Figure 4

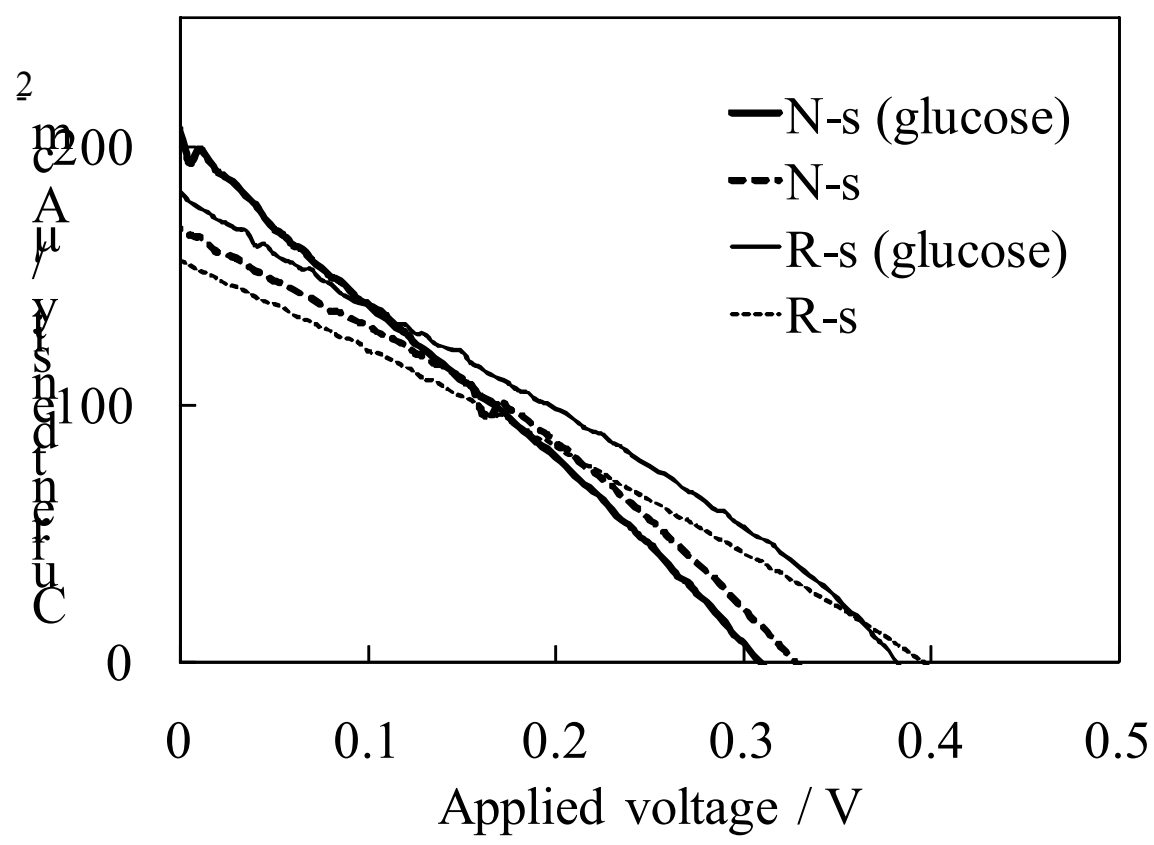


Figure 5
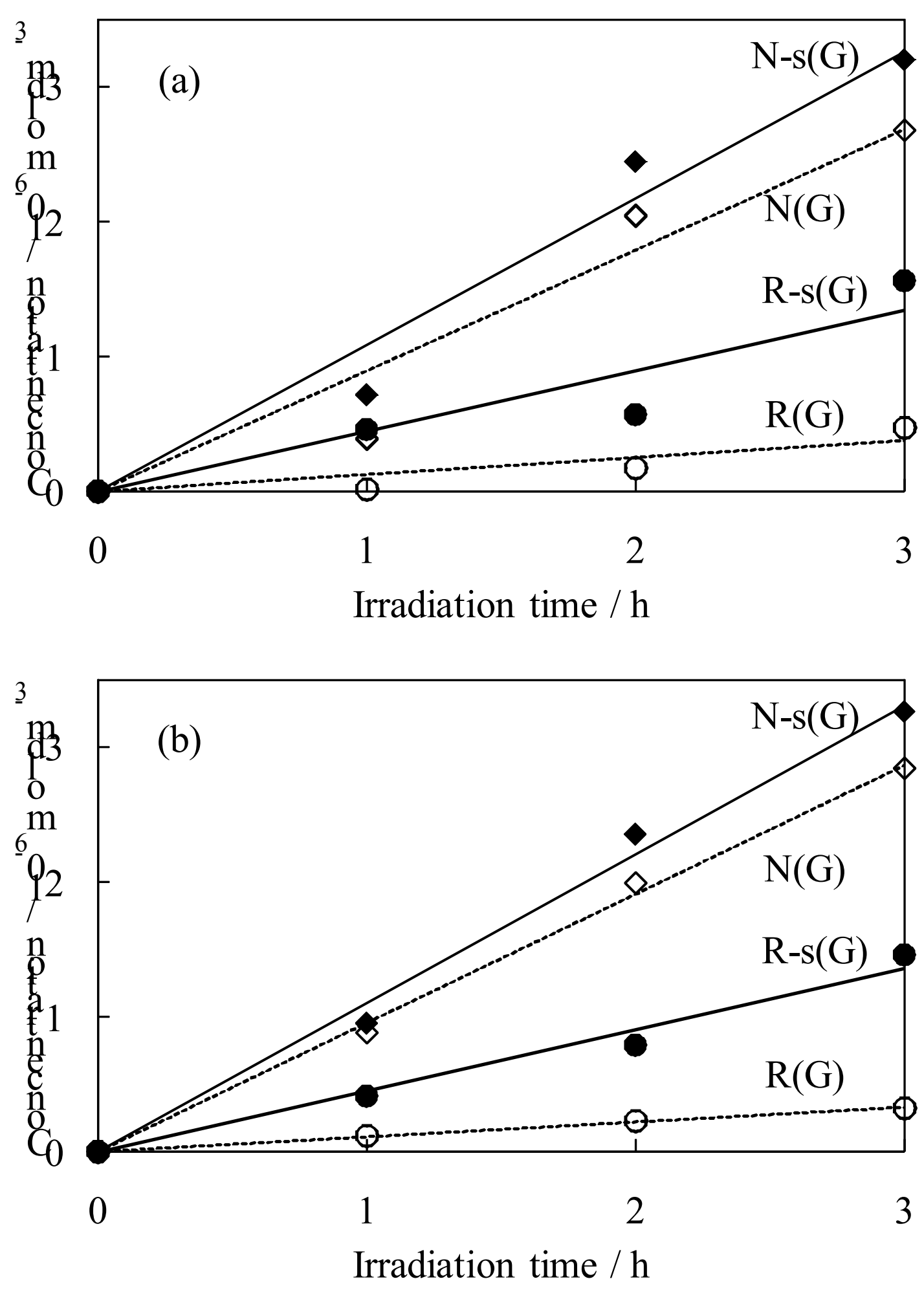